\title{
Prevalence of Pits and Fissure Caries in 7 to 14 Year Old Children - A Retrospective Study
}

\author{
Nur Liyana Hannah Binti Izham Akmal', Jessy P M D S ${ }^{3}$ and Revathi Duraisamy M D S \\ ${ }^{1}$ Saveetha Dental College, Saveetha Institute of Medical and Technical \\ Science, Saveetha University, Chennai India \\ ${ }^{2}$ Department of Prosthodontics Saveetha Dental College, Saveetha Institute of \\ Medical and Technical Science, Saveetha University Chennai India \\ ${ }^{3}$ Department of Pediatric Dentistry Saveetha Dental College, Saveetha Institute \\ of Medical and Technical Science, Saveetha University, Chennai India \\ Corresponding author email: jessyp.sdc@saveetha.com
}

\section{ABSTRACT}

Dental caries is considered to be a significant public health problem worldwide with cases being reported in both developed and developing countries. It has been reported that the occlusal surfaces with prominent pits and fissures morphology increases the risk of caries development. The aim of this study was to evaluate the prevalence of pits and fissure caries in 7-14 years children. It was a retrospective study conducted by reviewing 5,000 patient case records. A total of 1000 case records of patients for a period of December 2019 to April 2020 with complete records were reviewed and analysed. Patient's age, gender and presence of pits and fissure caries, caries in upper or lower arch were collected from the patient's case records. The obtained data was analysed using the SPSS version 23.0. Descriptive analysis was done for the assessment of age, gender and dental arches involved. Chi square test was used to evaluate the association of pits and fissure caries with age and gender. The overall prevalence of pits and fissures caries was about $61.7 \%$. Prevalence among 7-9 years old children was $25.1 \%$. Higher predilection for pits and fissures caries was seen in males (34.5\%) when compared to females (26.0\%). Most of the cases showed the presence of pits and fissures in both arches (63.7\%). Within the limits of the present study, pits and fissures caries exhibit higher prevalence in 7-9 years old children, male predilection and more common in both arches in an individual. There is a paramount need to educate the parents and caregivers about the importance of preventive measure in preventing caries and progression of decay in children.

\section{KEY WORDS: CHILDREN; PIT AND FISSURE CARIES; PREVALENCE; SCHOOL CHILDREN.}

\section{INTRODUCTION}

Dental caries is considered to be a significant public health problem worldwide with cases being reported in both developed and developing countries It is a complex multifactorial disease with numerous risk and preventive factors which affects individuals from all age groups, particularly in children; Dental caries are often associated with various risk factors including age, gender, dietary

Biosc Biotech Res Comm P-ISSN: 0974-6455 E-ISSN: 2321-4007

\section{crossef}

Identifiers and Pagination

Year: 2021 Vol: 14 No (10) Special Issue

Pages: 50-57

This is an open access article under Creative

Commons License Attribn 4.0 Intl (CC-BY).

DOI: $h t t p: / / d x . d o i . o r g / 10.21786 / b b r c / 14.10 .9$ habits and oral hygiene practices. In children, periods of tooth eruption, harmful dietary habits and types of muscle movements during suckling and swallowing are considered as the common factors of dental caries. These conditions are further exaggerated by the presence of dry mouth, poor oral hygiene and other factors which may contribute to the development of dental caries (Marsh, 2003; Sudha et al., 2005; Bagramian et al., 2009; Ayele et al., 2013; Al Agili, 2013; Al-Ansari, 2014; Christabel and Linda-Christabel, 2015; Nair et al., 2018; Aldossary et al., 2018; Raj et al., 2020).

Patterns of early childhood caries usually begin to change at the age of three which affects the first and second primary molars. A report stated that children with dental caries in the primary dentition tend to develop the same in the permanent dentition as they have demonstrated the factors required for developing dental caries in their early
Article Information

Received: $09^{\text {th }}$ Aug 2021

Accepted after revision: $11^{\text {th }}$ Oct 2021 
life along with the presence of biofilm and environmental factors such as diet responsible for caries formation even after the loss of primary teeth (Li and Wang, 2002; Ayele et al., 2013; Govindaraju etv al., 2017; Govindaraju et al., 2017a; Govindaraju et al., 2017b; Hall-Scullin et al., 2017; Mulani and Mathur, 2020).

The anatomy of the human dentition varies in which the anterior teeth exhibit smooth surfaces while the posterior teeth have smooth proximal surfaces and more tortuous morphology on the occlusal surface. The occlusal surfaces of the teeth are seen as incompletely coalesced areas represented by pits, fissures and grooves which act as stagnation sites for biofilm and cariogenic microorganisms. It has been reported that the occlusal surfaces with prominent pits and fissures morphology increases the risk of caries development to approximately $12.5 \%$ in the permanent dentition which accounts for most of the caries. The presence of plaque or biofilm on the pits and fissures of a partially erupted tooth also increases the risk of dental caries. Previous studies on the biofilm of pits and fissures caries described the presence of a unique architecture and specification of the biofilm based on the ecological niche where the roughened and opaque enamel underneath a layer of plaque is related to the presence of caries in the pits and fissures of a tooth (Dige et al., 2014; Carvalho et al., 2016; Wright, 2018; Mulani and Mathur, 2020).

Prevalence of dental caries in permanent teeth is mainly attributed to the individual morphology of the tooth in which pits and fissures on the occlusal surfaces of permanent teeth are particularly susceptible to the development of dental caries. The anatomy of the pits and fissures makes it difficult for proper oral hygiene practices such as tooth brushing to be carried out and less accessible for fluoride application as compared to the other surfaces of the tooth. Moreover, the development of pits and fissures caries is said to be more aggressive than the ability of fluoride to stimulate remineralization in these stagnation areas in order to prevent caries formation. Pits and fissures of the teeth increases the tendency of food accumulation which eventually becomes a shelter for microorganisms and stimulates the accumulation of dental plaque as they prevent oral hygiene practices to be carried out properly (Axelsson and Per Axelsson; 2004; Veiga et al., 2015; Somasundaram et al., 2015; Govindaraju and Gurunathan, 2017; Mahesh 2018; Wright, 2018; Raj et al., 2020).

Previously, it has been indicated that about $90 \%$ of dental caries in children are observed in pits and fissures areas which provides the rationale for sealant application due to its high prevalence in these areas. Another study revealed that pits and fissures caries contribute to approximately $80 \%$ to $90 \%$ of all caries in the permanent posterior teeth and $44 \%$ in the primary teeth. Genetic studies suggested that an individual's genetic determinants may affect the risk and resistance to dental caries by reporting that the heritable influence on pits and fissures caries development varies from $20 \%$ to $50 \%$. First permanent molars usually exhibit high susceptibility to dental caries in the occlusal pits and fissures, followed by second permanent molars due to their morphological features, early period of eruption and its position in the oral cavity (Kaste et al., 1996; Beauchamp et al., 2009; Shaffer et al., 2012; Aldossary et al., 2018; Jeevanandan and Govindaraju, 2018; Mulani and Mathur, 2020).

Various methods have been introduced to prevent the development of pits and fissures caries in which most studies recommended the application of pits and fissures sealants, particularly for pits and fissures that are deep and narrow in order to form a physical barrier that prevent further accumulation of plaque in specific anatomical areas of the tooth. Dental sealants refer to resin or glass-ionomer cement (GIC) based flowable materials applied on the occlusal surfaces of teeth as the first line of defense to prevent the development of dental caries, especially in children. Pits and fissures sealant acts by forming a micromechanical bond with the tooth which prevents the access by cariogenic microorganisms to their nutritional source and reduces the risk of caries development (Simonsen, 1978; Francis et al., 2007; Jeevanandan, 2017; Packiri et al., 2017; Ealla et al., 2018; Panchal et al., 2019; Mulani and Mathur, 2020).

Previous studies have discussed the effectiveness of pits and fissures sealants as a method of caries prevention and control in children which can be done in both individual and community level of interventions. Application of pits and fissures sealant as a primary preventive measure is highly recommended in order to prevent the development of dental caries, along with controlling and arresting the formation of incipient dental caries. Therefore, the pit and fissure sealant program are important among school children. Previously our team has a rich experience in working on various research projects across multiple disciplines (Ahovuo-Saloranta et al., 1999; Rose, 2001; Wright et al., 2016; Hou et al., 2017; Ravikumar et al., 2017; Aldossary et al., 2018; Gheena and Ezhilarasan, 2019; Ke et al., 2019; Malli Sureshbabu et al., 2019; Mehta et al., 2019; Samuel et al., 2019; Sharma et al., 2019; Varghese et al., 2019; Venu et al., 2019; Vignesh et al., 2019; Jain et al., 2019; Jose et al., 2020; Krishnaswamy et al., 2020; Muthukrishnan et al., 2020; Samuel et al., 2020; Sathish and Karthick, 2020). Now the growing trend in this area motivated us to pursue this project. Henceforth, this study was done to evaluate the prevalence of pits and fissure caries in 7 to 14 years old school going children of South Indian population.

\section{MATERIAL AND METHODS}

Study Design and Setting: A retrospective study was conducted by reviewing 5,000 patient case records of the Saveetha Dental College and Hospital, Chennai, India for a period of December 2019 to April 2020. A total of two examiners were involved in this study. An effort had been made to confirm that the sorted case records contained information on pits and fissure caries. Prior permission use of the case records analysis was obtained from the institutional review board with the ethical approval number of SDC/SIHEC/2020/DIASDATA/0619-0320.

Study Population and Sampling: A total of 1000 case records of patients with signed informed consent were sorted following the assessment of 5,000 case reports. The 
inclusion criteria of this study were children within 7 to 14 years of age and both genders. The adult patients and medically compromised patients were excluded from the study. Convenience sampling method was done for this study.

Data Collection: Information on the patient's age, gender and pits and fissures caries present or absent and involved dental arch were collected from the patient's case records. Age of the patients were categorized for statistical convenience as 7-9yrs, 10-11yrs and 12-14 yrs. Management of incomplete or censored data was excluded from the study.

Statistical Analysis: Tabulation and analysis of the collected data were done using Statistical Package for Social Sciences for Windows version 23.0 (SPSS Inc., Chicago, IL, USA). Descriptive analysis was done to assess the prevalence of pits and fissures caries in different age groups, gender and dental arches. Chi-square test was used to evaluate the association of pits and fissures caries with age and gender. Significant level test was set such that $\mathrm{p}>0.05$ is considered significant.

\section{RESULTS AND DISCUSSION}

Our present study involves a total of 1000 patients following the assessment of 5,000 case records based on the inclusion criteria of children within the 7 to 14 years of age and both genders while adult patients and medically compromised patients are excluded from this study. It is reported that pits and fissures caries are present in 617 (61.7\%) of the children in our study. The age groups in this study consist of 7-9 years (28.10\%), 10-11 (31.90\%) and 12-14 years $(40.00 \%)$. (Figure 1) Most of the patients are males $(60.30 \%)$ compared to females $(39.70 \%)$. (Figure 2$)$ In most of the cases, pits and fissures caries are present in both upper and lower arches of an individual in this study (63.70\%) and lower arch $(25.77 \%)$ is commonly involved with pits and fissures caries compared to upper arch (10.53\%) (Figure $3)$. It is observed that there is a positive correlation present between pits and fissures caries and age $(\mathrm{p}<0.05)$ (Figure 4) (Table 1).

High prevalence of pits and fissures caries is seen in children within $7-9$ years $(25.1 \%)$, followed by $12-14$ years $(19.9 \%)$ and $10-11$ years $(15.5 \%)$. It has been reported previously that the occurrence of dental caries in general tends to increase as the age increases with high prevalence among individuals in the low socioeconomic class. It was once generally accepted that pits and fissure of the teeth would become infected with bacteria within 10 years of erupting into the oral cavity. A previous study stated that only the first permanent molars are evaluated in their study involving children within 6 to 9 years of age as they are a key to the permanent dentition with high susceptibility to pits and fissures caries due to their morphology and have almost erupted in this age of children (Sayed and Salah, 2011; Babu et al., 2014; Aldossary et al., 2018; Raj et al., 2020).

According to Babu et al., sealant application should be done at the age of 3 to 4 years as they are the most important period for sealing the susceptible deciduous teeth, followed by 6 to 7 years age group for the first permanent molars and 11 to 13 years age groups for protecting the second permanent molars and premolars from pits and fissure caries. Previous studies revealed that nearly half of the children in their study on dental caries involved children from 11 to 15 years of age $(51.5 \%)$ which was associated with sociodemographic factors and lack of awareness on oral hygiene (Babu et al., 2014; Gurunathan and Shanmugaavel, 2016; Zeru, 2019; Raj et al., 2020).

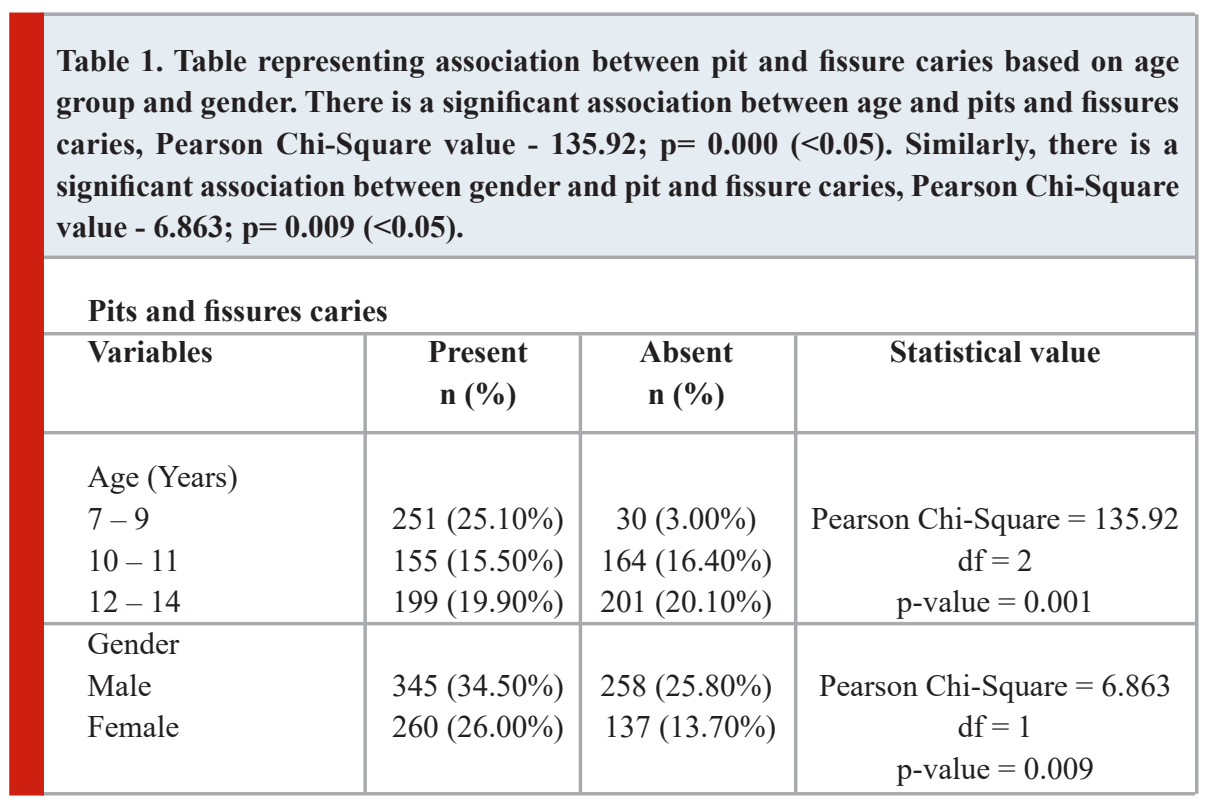

It is concluded that there is a statistically significant association between pits and fissures caries and gender $(p<0.05)$. (Figure 5). Higher predilection for pits and fissures caries is in males $(34.5 \%)$ as compared to females
(26.0\%). A previous study by Yee \& McDonald et al., stated that there is a significant difference $(p<0.001)$ between genders with higher prevalence of dental caries seen in males compared to females, which is in accordance with 
our study. This finding was associated with the difference in diet between males and females in which males often consume diets with more sweets than females with improper oral and dental care. Dhar et al., also mentioned higher caries prevalence in males $(48.1 \%)$ compared to females $(45.3 \%)$ but no significant difference between genders. A study described the greater attention that female adolescents have on their oral health care compared to males which is justified by the higher prevalence of pits and fissures sealant application in females compared to males. A report stated that dental caries are also affected by the timing of tooth eruption in which females tend to undergo earlier eruption of the molars compared to males which increases their risk of developing pits and fissures caries earlier than males (Yee and McDonald, 2002; Dhar et al., 2007; Peres et al., 2007; Poutanen et al., 2007; Malvania et al., 2014; Veiga et al., 2015; Raj et al., 2020; Gürcan and Bayram, 2021).

Figure 1: Figure showing the frequency distribution of different age groups. $\mathrm{X}$ axis represents the age groups. $\mathrm{Y}$ axis represents the number of patients in each age group. The age groups in this study consist of 7-9 years $(28.10 \%)$, $10-11(31.90 \%)$ and $12-14$ years $(40.00 \%)$.

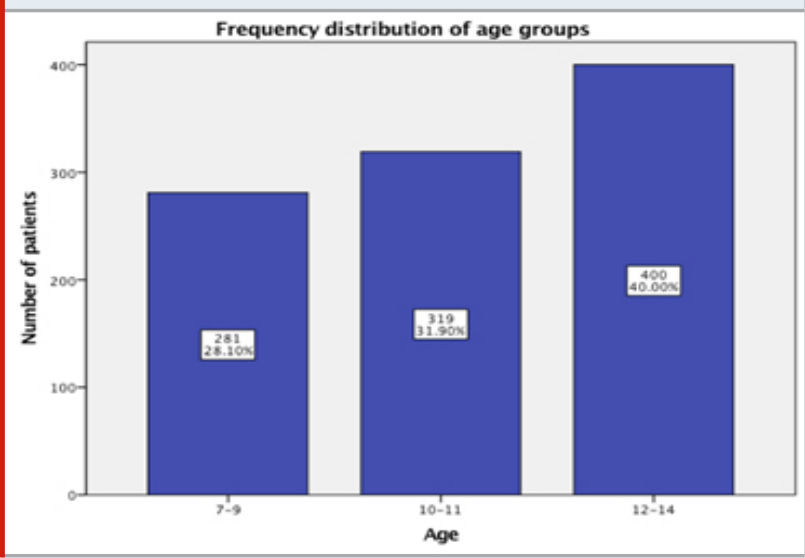

Figure 2: Figure showing the frequency distribution of genders. $\mathrm{X}$ axis represents genders. $\mathrm{Y}$ axis represents the number of patients of each gender. Most of the patients in this study are males $(60.30 \%)$ as compared to females $(39.70 \%)$.

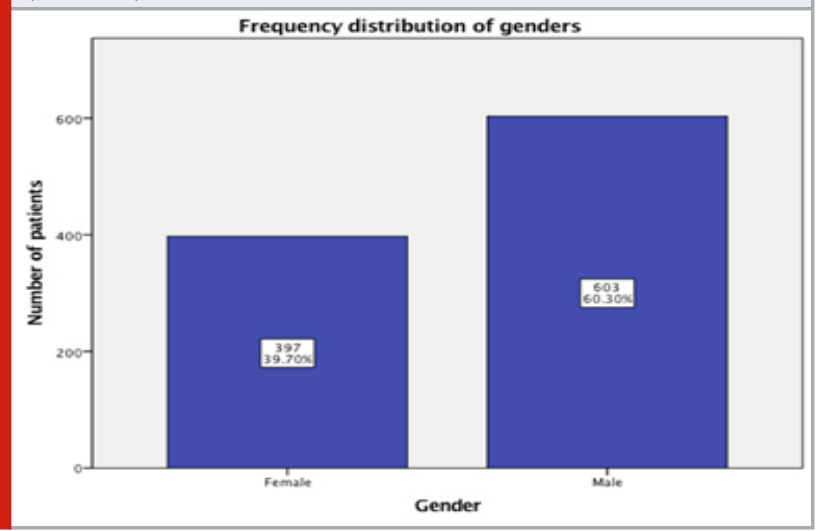

Comparing both arches, higher prevalence of pits and fissure caries are seen in the lower arch $(25.77 \%)$ than the upper
Figure 3: Figure showing the frequency of pits and fissures caries based on dental arches. $X$ axis represents the dental arches. $\mathrm{Y}$ axis represents the number of patients in each dental arch involved. In most of the cases, pits and fissures caries are present in both upper and lower arches of an individual in this study (63.70\%) and lower arch (25.77\%) is commonly involved with pits and fissures caries compared to upper $\operatorname{arch}(\mathbf{1 0 . 5 3 \% )}$.

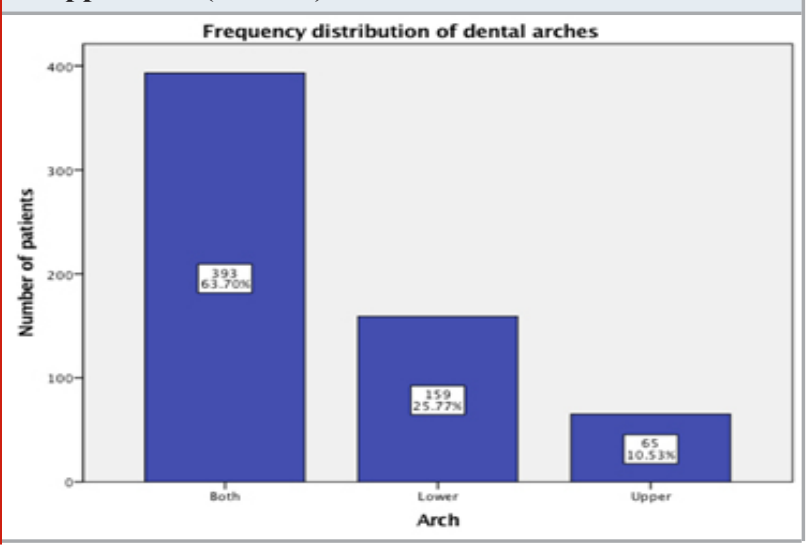

Figure 4: Figure showing the association between pits and fissures caries and its frequency among different age groups. $\mathrm{X}$ axis represents the age groups. $\mathrm{Y}$ axis represents the number of patients in each age group. Chi square test shows there is a significant association between age and pits and fissures caries, Pearson Chi-Square value - 135.92; $p=$ $0.000(<0.05)$. Prevalence of pits and fissures caries (Green) were more among children within the 7-9 years age group $(25.10 \%)$ when compared to the other age groups.

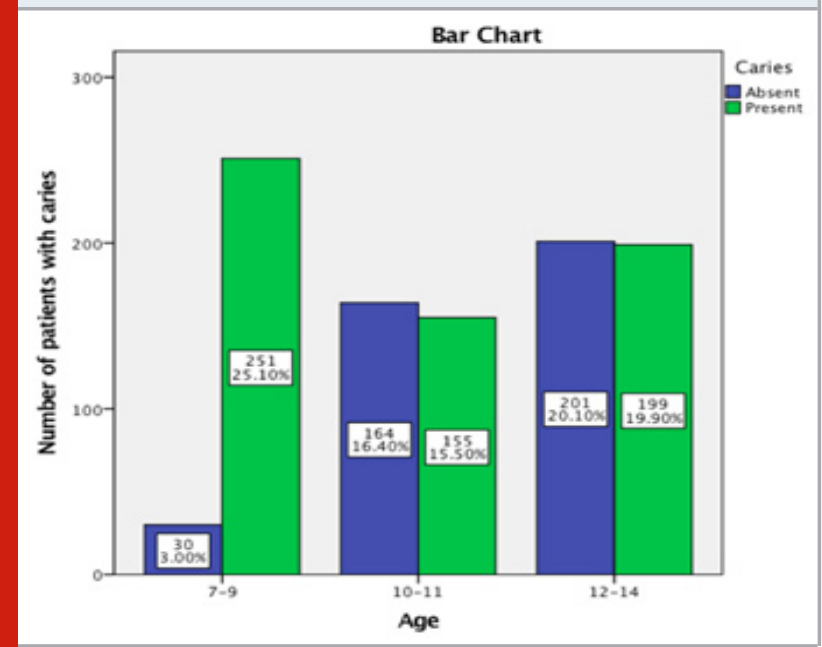

arch $(10.53 \%)$, although in most cases pits and fissures caries are seen in both arches (63.70\%) (Figure 3). A study by Aldossary et al., stated that higher prevalence of caries is seen in the lower arch (14.4\%) as compared to the upper arch $(7.7 \%)$ which is in accordance with our study. This finding is mainly attributed to the difference in the morphology of the teeth and the time of eruption with mandibular teeth erupting earlier than the maxillary teeth which increases their time of exposure in oral cavity. The morphology of 
permanent molars includes prominent pits and fissures with tortuous defects extending from the surface of the tooth to the dentinoenamel junction seen in the occlusal surfaces, buccal or facial surfaces of mandibular molars and palatal surface of maxillary molars which increases the risk of developing pits and fissures caries in these areas.

Figure 5: Figure showing the association between pits and fissures caries and its frequency among genders. $X$ axis represents the genders. $Y$ axis represents the number of patients of each gender. Chi square test shows there is a significant association between gender and pit and fissure caries, Pearson Chi-Square value $=6.863 ; p=0.009$ $(<\mathbf{0 . 0 5})$. Prevalence of pits and fissures caries (Green)were more among males $(34.50 \%)$ when compared to females (26.00\%).

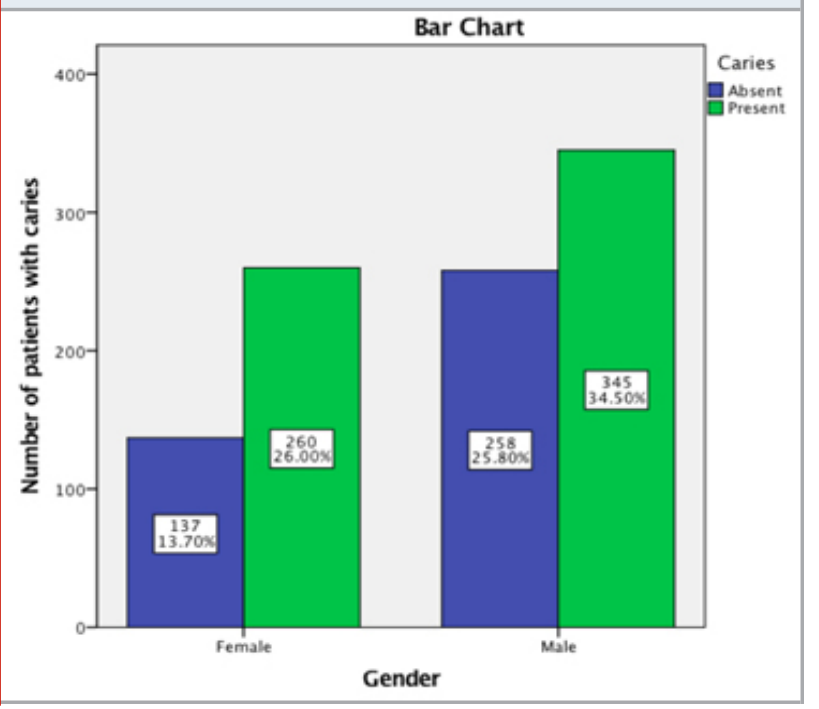

The morphology of the pits and fissures on the surfaces of these teeth increases the risk of food accumulation which results in the formation of plaque over a period of time. This condition is influenced by the frequency and timing of fermentable carbohydrates intake which will be metabolized by specific microorganisms such as Streptococcus mutans leading to fermentation that releases large amount of acid and lowers the local $\mathrm{pH}$ that results in dissolution of the enamel and dentin minerals (Franco e Franco et al., 2007; Colak et al., 2013; Maher et al., 1992; Aldossary et al., 2018; Subramanyam et al., 2018; Santa et al., 2021).

Pits and fissures sealant is considered to be an effective and economical method for the primary prevention of dental caries which needs to be incorporated in oral health community programs. A study by Azarpazhooh et al., strongly supports the placement of sealants on primary and permanent molar teeth as both cost-effective and efficacious in the prevention of dental caries. This is further supported by Aldossary et al mentioning that school-based or national sealant programs should be highly promoted and implemented as an effective preventive approach, along with oral health education (Azarpazhooh and Main, 2008; Veiga et al., 2015; Carvalho et al., 2016; Hall-Scullin et al.,
2017; Govindaraju and Gurunathan, 2017; Aldossary et al., 2018; Mahesh, 2018; Raj et al., 2020).

A study explained that the application of primary preventive methods, particularly pits and fissures sealant complemented with oral health education will help to reduce the financial impact of oral treatments and risk of developing dental caries. The present study had few limitations of study design. Since it is a retrospective study, follow up of subjects was not possible to extrapolate the study results. This study also failed to assess the other confounding variables such as education, socioeconomic status and habits of the patients. Further prospective study including all possible factors for pits and fissures caries has to be investigated to prove the hypothesis.Our institution is passionate about high quality evidence based research and has excelled in various fields (Veiga et al., 2015; Pc et al., 2018; Ramesh et al., 2018; Ezhilarasan et al., 2019; Ramadurai et al., 2019; Sridharan et al., 2019; Vijayashree et al., 2019; Mathew et al., 2020). We hope this study adds to this rich legacy.

\section{CONCLUSION}

Within the limits of the present study, overall prevalence of pits and fissures caries was about $61.7 \%$, pits and fissures caries were exhibited higher in 7-9 years old children, male predilection and more common in both arches in an individual. There is a paramount need to educate the parents and caregivers about the importance of pit and fissure application as a preventive measure in preventing caries and progression of decay in children.

Conflict of Interest: There was no conflict of interest.

\section{REFERENCES}

Ahovuo-Saloranta, A. et al. (1999). Pit and fissure sealants for preventing dental decay in the permanent teeth of children and adolescents. Cochrane Database of Systematic Reviews. doi: 10.1002/14651858.cd001830. Al Agili, D. E. (2013). A systematic review of populationbased dental caries studies among children in Saudi Arabia. The Saudi dental journal, 25(1), pp. 3-11.

Al-Ansari, A. (2014). Prevalence, severity, and secular trends of dental caries among various Saudi populations: A literature review. Saudi Journal of Medicine and Medical Sciences, p. 142. doi: 10.4103/1658-631x.142496.

Aldossary S. M. et al. (2018). Prevalence of Dental Caries and Fissure Sealants in the First Permanent Molars among Male Children in Riyadh, Kingdom of Saudi Arabia. International journal of clinical pediatric dentistry, 11(5), pp. 365-370.

Axelsson, P. and Per Axelsson D D (2004). Preventive Materials, Methods, and Programs. Quintessence Publishing Company.

Ayele, F. A. et al. (2013). Predictors of Dental caries among children 7-14 years old in Northwest Ethiopia: a community based cross-sectional study. BMC Oral Health. doi: 10.1186/1472-6831-13-7. 
Azarpazhooh, A. and Main, P. A. (2008). Pit and fissure sealants in the prevention of dental caries in children and adolescents: a systematic review. Journal, 74(2), pp. 171-177.

Babu, G. et al. (2014). Pit and fissure sealants in pediatric dentistry. SRM Journal of Research in Dental Sciences, p. 253. doi: 10.4103/0976-433x.145131.

Bagramian, R. A., Garcia-Godoy, F. and Volpe, A. R. (2009). The global increase in dental caries. A pending public health crisis. American journal of dentistry, 22(1), pp. 3-8.

Beauchamp, J. et al. (2009). Evidence-based clinical recommendations for the use of pit-and-fissure sealants: a report of the American Dental Association Council on Scientific Affairs. Dental clinics of North America, 53(1), pp. 131-47, x.

Carvalho, J. C. et al. (2016). Occlusal Caries: Biological Approach for Its Diagnosis and Management. Caries research, 50(6), pp. 527-542.

Christabel, S. L. and Linda Christabel, S. (2015). Prevalence of Type of Frenal Attachment and Morphology of Frenum in Children, Chennai, Tamil Nadu. World Journal of Dentistry, pp. 203-207. doi: 10.5005/jpjournals-10015-1343.

Colak, H. et al. (2013). Early childhood caries update: A review of causes, diagnoses, and treatments. Journal of natural science, biology, and medicine, 4(1), pp. 29-38.

Dhar, V. et al. (2007). Prevalence of dental caries and treatment needs in the school-going children of rural areas in Udaipur district. Journal of the Indian Society of Pedodontics and Preventive Dentistry, 25(3), pp. 119-121.

Dige, I., Grønkjær, L. and Nyvad, B. (2014). Molecular Studies of the Structural Ecology of Natural Occlusal Caries. Caries Research, pp. 451-460. doi: 10.1159/000357920.

Ealla, K. K. R. et al. (2018). Knowledge Analysis of Pit and Fissure Sealants among the Dental Students of South India. Journal of International Society of Preventive \& Community Dentistry, 8(6), pp. 508-512.

El Sayed M Salah A, E.-Y. M. R. M. (2011). Dental Caries Prevalence among a group of Egyptian Nurseries Children. Life science journal, 8(1), pp. 512-519.

Ezhilarasan, D., Apoorva, V. S. and Ashok Vardhan, N. (2019). Syzygium cumini extract induced reactive oxygen species-mediated apoptosis in human oral squamous carcinoma cells. Journal of oral pathology \& medicine: official publication of the International Association of Oral Pathologists and the American Academy of Oral Pathology, 48(2), pp. 115-121.

Francis, B. et al. (2007). Clinical Companion Study Guide for Mosby's Dental Hygiene: Concepts, Cases and Competencies. Mosby.

Franco e Franco, T. C. C. et al. (2007). Detection of
Streptococcus mutans and Streptococcus sobrinus in dental plaque samples from Brazilian preschool children by polymerase chain reaction. Brazilian dental journal, 18(4), pp. 329-333.

Gheena, S. and Ezhilarasan, D. (2019). Syringic acid triggers reactive oxygen species-mediated cytotoxicity in HepG2 cells. Human \& experimental toxicology, 38(6), pp. 694-702.

Govindaraju, L. and Gurunathan, D. (2017). Effectiveness of Chewable Tooth Brush in Children-A Prospective Clinical Study. Journal of clinical and diagnostic research: JCDR, 11(3), pp. ZC31-ZC34.

Govindaraju, L., Jeevanandan, G. and Subramanian, E. (2017). Clinical Evaluation of Quality of Obturation and Instrumentation Time using Two Modified Rotary File Systems with Manual Instrumentation in Primary Teeth. Journal of clinical and diagnostic research: JCDR, 11(9), pp. ZC55-ZC58.

Govindaraju, L., Jeevanandan, G. and Subramanian, E. M. G. (2017a). Comparison of quality of obturation and instrumentation time using hand files and two rotary file systems in primary molars: A single-blinded randomized controlled trial. European journal of dentistry, 11(3), pp. 376-379.

Govindaraju, L., Jeevanandan, G. and Subramanian, E. M. G. (2017b). Knowledge and practice of rotary instrumentation in primary teeth among indian dentists: A questionnaire survey. Journal of International Oral Health, p. 45. doi: 10.4103/jioh.jioh_4_17.

Gürcan, A.T. and Bayram, M., (2021). Children's dental treatment requirements of first permanent molars with poor prognosis. Clinical Oral Investigations, pp.1-10.

Gurunathan, D. and Shanmugaavel, A. K. (2016). Dental neglect among children in Chennai. Journal of the Indian Society of Pedodontics and Preventive Dentistry, 34(4), pp. 364-369.

Hall-Scullin, E. et al. (2017). Longitudinal Study of Caries Development from Childhood to Adolescence. Journal of Dental Research, pp. 762-767. doi: $10.1177 / 0022034517696457$.

Hou, J. et al. (2017). Systemic review of the prevention of pit and fissure caries of permanent molars by resin sealants in children in China. Journal of investigative and clinical dentistry, 8(1). doi: 10.1111/jicd.12183.

Jeevanandan, G. (2017). Kedo-S Paediatric Rotary Files for Root Canal Preparation in Primary Teeth - Case Report. Journal of clinical and diagnostic research: JCDR, 11(3), pp. ZR03-ZR05.

Jeevanandan, G. and Govindaraju, L. (2018). Clinical comparison of Kedo-S paediatric rotary files vs manual instrumentation for root canal preparation in primary molars: a double blinded randomised clinical trial. European Archives of Paediatric Dentistry, pp. 273-278. 
doi: 10.1007/s40368-018-0356-6.

Jose, J., Ajitha and Subbaiyan, H. (2020). Different treatment modalities followed by dental practitioners for Ellis class 2 fracture - A questionnaire-based survey. The open dentistry journal, 14(1), pp. 59-65.

Kaste, L. M. et al. (1996). Coronal Caries in the Primary and Permanent Dentition of Children and Adolescents 1-17 Years of Age: United States, 19881991. Journal of Dental Research, pp. 631-641. doi: $10.1177 / 002203459607502$ s03.

Ke, Y. et al. (2019). Photosynthesized gold nanoparticles from Catharanthus roseus induces caspase-mediated apoptosis in cervical cancer cells (HeLa). Artificial cells, nanomedicine, and biotechnology, 47(1), pp. 19381946.

Krishnaswamy, H. et al. (2020) 'Investigation of air conditioning temperature variation by modifying the structure of passenger car using computational fluid dynamics', Thermal science, 24(1 Part B), pp. 495-498.

Li, Y. and Wang, W. (2002). Predicting caries in permanent teeth from caries in primary teeth: an eight-year cohort study. Journal of dental research, 81(8), pp. 561-566.

Maher, R. et al. (1992). Prevalence of mutans streptococci and dental caries in Pakistani children. Journal of the Pakistan Medical Association, 42(9), pp. 213-215.

Mahesh R, M. M. (2018). Fluoride, fluoridated toothpaste efficacy and its safety in children - Review. International Journal of Pharmaceutical Research, 10(4), pp. 109114.

Malli Sureshbabu, N. et al. (2019). Concentrated Growth Factors as an Ingenious Biomaterial in Regeneration of Bony Defects after Periapical Surgery: A Report of Two Cases. Case reports in dentistry, 2019, p. 7046203.

Malvania, E. et al. (2014). Prevalence of dental caries and treatment needs among 12-year-old school going children in Vadodara City, Gujarat, India: A cross-sectional study. Indian Journal of Oral Sciences, p. 3. doi: 10.4103/09766944.129938.

Marsh, P. D. (2003). Are dental diseases examples of ecological catastrophes? Microbiology, 149(Pt 2), pp. 279-294.

Mathew, M. G. et al. (2020). Evaluation of adhesion of Streptococcus mutans, plaque accumulation on zirconia and stainless steel crowns, and surrounding gingival inflammation in primary. Clinical oral investigations.

Mehta, M. et al. (2019). Oligonucleotide therapy: An emerging focus area for drug delivery in chronic inflammatory respiratory diseases. Chemico-biological interactions, 308, pp. 206-215.

Muthukrishnan, S. et al. (2020). Support vector machine for modelling and simulation of heat exchangers. Thermal science, 24(1 Part B), pp. 499-503.

Mulani, R. and Mathur, A., (2020). Retention of Various
Pit and Fissure Sealants in Deciduous Teeth. A Systematic Review. EXECUTIVE EDITOR, 11(7), p.676.

Nair, M. et al. (2018). Comparative evaluation of postoperative pain after pulpectomy with k-files, kedo-s files and mtwo files in deciduous molars -a randomized clinical trial. Brazilian Dental Science, p. 411. doi: 10.14295/ bds.2018.v21i4.1617.

Packiri, S., Gurunathan, D. and Selvarasu, K. (2017). Management of Paediatric Oral Ranula: A Systematic Review. Journal of clinical and diagnostic research: JCDR, 11(9), pp. ZE06-ZE09.

Panchal, V., Jeevanandan, G. and Subramanian, E. (2019). Comparison of instrumentation time and obturation quality between hand K-file, H-files, and rotary Kedo-S in root canal treatment of primary teeth: A randomized controlled trial. Journal of the Indian Society of Pedodontics and Preventive Dentistry, 37(1), pp. 75-79.

Pc, J., Marimuthu, T. and Devadoss, P. (2018). Prevalence and measurement of anterior loop of the mandibular canal using CBCT: A cross sectional study. Clinical implant dentistry and related research. Available at: https:// europepmc.org/article/med/29624863.

Peres, M. A. et al. (2007). The relation between family socioeconomic trajectories from childhood to adolescence and dental caries and associated oral behaviours. Journal of epidemiology and community health, 61(2), pp. 141-145.

Poutanen, R. et al. (2007). Oral health-related knowledge, attitudes, behavior, and family characteristics among Finnish schoolchildren with and without active initial caries lesions. Acta Odontologica Scandinavica, pp. 87-96. doi: 10.1080/00016350601058077.

Ramadurai, N. et al. (2019). Effectiveness of 2\% Articaine as an anesthetic agent in children: randomized controlled trial. Clinical oral investigations, 23(9), pp. 3543-3550.

Raj, B., Srinivasan, S.R. and MS, N., (2020). THE USE OF PIT AND FISSURE SEALANT AMONG ADULT POPULATION-A RETROSPECTIVE STUDY. European Journal of Molecular \& Clinical Medicine, 7(1), pp.19261932.

Ramesh, A. et al. (2018). Comparative estimation of sulfiredoxin levels between chronic periodontitis and healthy patients - A case-control study. Journal of periodontology, 89(10), pp. 1241-1248.

Ravikumar, D., Jeevanandan, G. and Subramanian, E. M. G. (2017). Evaluation of knowledge among general dentists in treatment of traumatic injuries in primary teeth: A cross-sectional questionnaire study. European journal of dentistry, 11(2), pp. 232-237.

Rose, G. (2001). Sick individuals and sick populations. 1985. Bulletin of the World Health Organization, 79(10), pp. 990-996.

Samuel, M. S. et al. (2019). Efficient removal of Chromium 
(VI) from aqueous solution using chitosan grafted graphene oxide (CS-GO) nanocomposite. International journal of biological macromolecules, 121, pp. 285-292. Samuel, S. R., Acharya, S. and Rao, J. C. (2020). School Interventions-based Prevention of Early-Childhood Caries among 3-5-year-old children from very low socioeconomic status: Two-year randomized trial. Journal of public health dentistry, 80(1), pp. 51-60.

Santa P, J., Sowmya, K. and Jeevanandan, G., (2021). Analysis of Composite Restorations in Patients below 21 Years of Age-A Retrospective Study. Annals of the Romanian Society for Cell Biology, pp.6456-6470.

Sathish, T. and Karthick, S. (2020). Wear behaviour analysis on aluminium alloy 7050 with reinforced $\mathrm{SiC}$ through taguchi approach. Journal of Japan Research Institute for Advanced Copper-Base Materials and Technologies, 9(3), pp. 3481-3487.

Shaffer, J. R. et al. (2012). Genetic susceptibility to dental caries on pit and fissure and smooth surfaces. Caries research, 46(1), pp. 38-46.

Sharma, P. et al. (2019). Emerging trends in the novel drug delivery approaches for the treatment of lung cancer. Chemico-biological interactions, 309, p. 108720.

Simonsen, R. J. (1978) Clinical applications of the acid etch technique. Quintessence Publishing (IL).

Somasundaram, S. et al. (2015). Fluoride Content of Bottled Drinking Water in Chennai, Tamilnadu. Journal of clinical and diagnostic research: JCDR, 9(10), pp. ZC32-4.

Sridharan, G. et al. (2019). Evaluation of salivary metabolomics in oral leukoplakia and oral squamous cell carcinoma. Journal of oral pathology \& medicine: official publication of the International Association of Oral Pathologists and the American Academy of Oral Pathology, 48(4), pp. 299-306.

Subramanyam, D. et al. (2018). Comparative evaluation of salivary malondialdehyde levels as a marker of lipid peroxidation in early childhood caries. European journal of dentistry, 12(1), pp. 67-70.

Sudha, P., Bhasin, S. and Anegundi, R. T. (2005). Prevalence of dental caries among 5-13-year-old children of Mangalore city. Journal of the Indian Society of Pedodontics and Preventive Dentistry, 23(2), pp. 74-79. Varghese, S. S., Ramesh, A. and Veeraiyan, D. N. (2019).
Blended Module-Based Teaching in Biostatistics and Research Methodology: A Retrospective Study with Postgraduate Dental Students. Journal of dental education, 83(4), pp. 445-450.

Veiga, N. J. et al. (2015). Prevalence of Dental Caries and Fissure Sealants in a Portuguese Sample of Adolescents. PLOS ONE, p. e0121299. doi: 10.1371/ journal.pone.0121299.

Venu, H., Raju, V. D. and Subramani, L. (2019). Combined effect of influence of nano additives, combustion chamber geometry and injection timing in a DI diesel engine fuelled with ternary (diesel-biodiesel-ethanol) blends. Energy, 174, pp. 386-406.

Venu, H., Subramani, L. and Raju, V. D. (2019). Emission reduction in a DI diesel engine using exhaust gas recirculation (EGR) of palm biodiesel blended with $\mathrm{TiO} 2$ nano additives. Renewable Energy, 140, pp. 245-263.

Vignesh, R. et al. (2019). Management of Complicated Crown-Root Fracture by Extra-Oral Fragment Reattachment and Intentional Reimplantation with 2 Years Review. Contemporary clinical dentistry, 10(2), pp. 397-401.

Vijayakumar Jain, S. et al. (2019). Evaluation of ThreeDimensional Changes in Pharyngeal Airway Following Isolated Lefort One Osteotomy for the Correction of Vertical Maxillary Excess: A Prospective Study. Journal of maxillofacial and oral surgery, 18(1), pp. 139-146.

Vijayashree P. J. (2019). In silico validation of the non-antibiotic drugs acetaminophen and ibuprofen as antibacterial agents against red complex pathogens. Journal of periodontology, 90(12), pp. 1441-1448.

Wright, J. T. (2018). The Burden and Management of Dental Caries in Older Children. Pediatric clinics of North America, 65(5), pp. 955-963.

Wright, J. T. et al. (2016). Sealants for Preventing and Arresting Pit-and-fissure Occlusal Caries in Primary and Permanent Molars. Pediatric dentistry, 38(4), pp. 282-308.

Yee, R. and McDonald, N. (2002). Caries experience of 5-6-year-old and 12-13-year-old schoolchildren in central and western Nepal. International dental journal, 52(6), pp. 453-460.

Zeru, T. (2019). Prevalence of Dental Caries and Associated Factors among Aksum Primary School Students, Aksum Town, Ethiopia. Journal of Dental and Oral Health, 5(2). 